\title{
Good mobility practices at Poltificia Universidad Javeriana (transportation)
}

\author{
Alexandra Leal ${ }^{1, *}$, and Sandra Catalina Acosta ${ }^{2}$ \\ 1 Pontificia Universidad Javeriana, Carrera 7 \# 40-62, Bogotá - Colombia \\ 2 Pontificia Universidad Javeriana, Carrera 7 \# 40-62, Bogotá - Colombia
}

\begin{abstract}
This paper presents the strategies that the Pontificia Universidad Javeriana has been implementing since 2012, aimed to contributing from the academy to the mobility of the city of Bogotá, in order to improve the quality of life of our university community and to reduce the impact on the environment.
\end{abstract}

\section{Introduction}

The Pontificia Universidad Javeriana is located in the city of Bogotá, capital of Colombia. It is a city with about 10 million inhabitants counting the annexed municipalities. It occupies an area of 1,587 square kilometres. The city along with its rapid growth has experienced traffic problems that became critical in the last decade of the 20th century; problems that were worsen by not having a real urban public transport system that would serve as an alternative to the use of the private vehicle. The city had low levels of competitiveness and an unsatisfactory quality of life for the vast majority of its inhabitants. In 2000, the city completed the TRANSMILENIO mass transport system project, which included the construction of a special infrastructure specifically and exclusively for its operation. This infrastructure was based on specialized trunk corridors and was equipped with single-use lanes, stations, bridges, bike paths and special pedestrian access platforms; all of them designed to facilitate the use of the system by users [1]. TRANSMILENIO started its operation in the year 2000. Currently, the company TRANSMILENIO, owned by the city, has 113 kilometres of trunk/main roads in operation and is the manager of the integrated public transport system IPTS (in Spanish SITP; here after used as such) of the city, which in turn integrates different types of transport (urban, special, complementary, trunk, feeder) seeking the effective coverage of transportation in Bogotá. The SITP has a unique means of payment through smart cards [1].

Despite the implementation of the integrated system and the great efforts of local governments, these have not been sufficient to meet efficiently the transportation problems of the city. According to studies carried out by the Observatory of Mobility of Bogota, the city has about 2,200,000 vehicles, of which $94 \%$ correspond to private vehicles, which only mobilize $24 \%$ of the population. $69 \%$ is mobilized in the integrated system [2]. The average speed of vehicles in the city was 31.1 kilometres per hour in 2008. This rate has been decreasing due to the growth in the number of vehicles, and in 2016, it was 24.5 kilometres per hour. According to the last global report of the firm INRIX that analyses 1360 cities of 38 countries, Bogota ranks sixth among the most trafficdensed cities. The same study concludes that the solution to the problem should be viewed collectively through alternative solutions to the vehicle. This solution would aim at strengthening the public transport system by improving the conditions for users to have more ways to use alternative means such as cycling and walking, and modifying the habits regarding the use of personal vehicle.

\section{The problem of mobility}

The Pontificia Universidad Javeriana is not oblivious to this problem. The university community is made up of 30,000 people according to what is indicated in table 1:

Table 1. Javeriana university community

\begin{tabular}{|l|l|}
\hline Description & Quantity \\
\hline Undergraduate and graduate students & 24,203 \\
\hline Teachers & 3,458 \\
\hline Administrative employees & 1,637 \\
\hline Total community & 29,298 \\
\hline
\end{tabular}

Source: Planning Secretariat, Pontificia Universidad Javeriana.

The size of the University and its location in the city of Bogotá cause that the members of the university community invest very long times in their commuting to and from the University. Moreover, productivity and quality of life within the University are effected 
generating as well traffic jams in all its area of influence. Being aware of this, and in the framework of environmental sustainability and social responsibility programs, in 2012 the University formally gave life to the "Javeriana Mobility Program". This program led and managed by the University Services Directorate embraces the following objectives as guiding principles: a. Contribute to the improvement of the mobility of the city of Bogotá, b. Encourage the use of alternative and sustainable means of transport. c. Sensitize the university community about good practices in mobility, d. Improve the quality of life of the members of the University community. Since then, the "Javeriana Mobility Program" is part of university planning, particularly by the University Services Department.

\section{Strategies for mobility}

In 2012, the University was linked to the PEMS Network (in Spanish, Sustainable Mobility Enterprise Plans, and hereafter used as such), which promotes the implementation of corporate policies and practical actions aimed at reducing the impact of employees' commuting/mobility, to and from work; in their quality of life and in the mobility of the city [3]. With this initiative, the private sector has the opportunity to be an active agent that contributes to a more sustainable mobility. The PEMS network was born in 2010 as a collaborative project between the private sector and the academy and managed to link 40 companies from different sectors. A Sustainable Mobility Business Plan brings together strategies that aimed at rationalizing journeys to the workplace and mitigating the negative impacts that these generate in the three areas of sustainability: economic, social and environmental, in this case benefiting the university community and actively contributing to the city.

The companies of the PEMS Network have worked together for the mobility of the city, consolidating a culture of sustainable development by exchanging experiences, and best practices. Through workshops with experts, awareness campaigns, training sessions, good practices have been shared and strategies have been designed to provide solutions to the mobility problem.

In 2015, the Javeriana University, along with Network experts, made its mobility diagnosis based on a survey and interviews that were carried out with some areas of the University. The survey gathered 3,091 people from the university community, (approximately $10 \%$ of the population). It ensured the statistical representation of the results of the same. In 2013, a first diagnosis was presented, yet the sample was not representative; as such, the results did not generate a possibility of comparison. The survey asked members of the university community aspects such as: a. Time distribution on trips/commuting. b. Modes of mobilization to and from the University. c. Distances, times, costs of communting. $d$. Infrastructure for mobility.
The results of this diagnosis allowed us to obtain relevant information about the mobility of the university community and, along with the methodology applied by network experts, four synthesis indicators were obtained that allowed quantifying the social and environmental impact of employee and students' mobility of the Javeriana University [4]. These four indicators are carbon footprints, energy, quality of life and equity. The measurement of these four footprints generated the following results:

- The carbon footprint indicates the tons of $\mathrm{CO} 2$ equivalent emitted per capita and the amount of land with vegetation cover necessary to absorb these emissions. Each year, the University's employee and students emit 4,848 tons of $\mathrm{CO} 2$ equivalent, for which 3,068 hectares of forest are needed for their absorption.

- The energy footprint corresponds to fuel consumption for trips to and from the University. For these trips, 713,925 gallons of fuel are consumed per year, of which $67 \%$ is due to the mobility of people in personal vehicles $(63 \%$ vehicle and $4 \%$ motorcycle).

- The quality of life footprint refers to the average time a person spends on commuting for work and study per year. On average, an employee or a student spends 12 days a year moving to and from the University.

- The equity footprint refers to the percentage of income that a person must allocate to pay for transportation to and from the University. On average, an employee or student at the University spends $15 \%$ of their monthly income on transportation.

- Other findings that were evidenced in the diagnosis made in 2015 were the following:

- $\quad 37.6 \%$ of trips are made in the integrated transport system of the city, $20.3 \%$ in other types of buses that are not part of the integrated system, $17.3 \%$ in automobiles, $7.3 \%$ on bicycle and $8.9 \%$ on foot. Regarding the vehicles that arrive at the University, the average of passengers is 2; in one day, employees and students travel an average of 7.8 kilometers per trip to get to the University from home; each trip has an average duration of 44 minutes.

- The aforementioned indicators or traces, as well as the findings found in the diagnosis made, were the basis to define the strategies to continue as well as the new ones to be implemented. The following typology of strategies was defined: a. Efficient and responsible use of the car. b. Use of alternative means of transport. c. Change of mobility habits and d. Infrastructure improvements. 


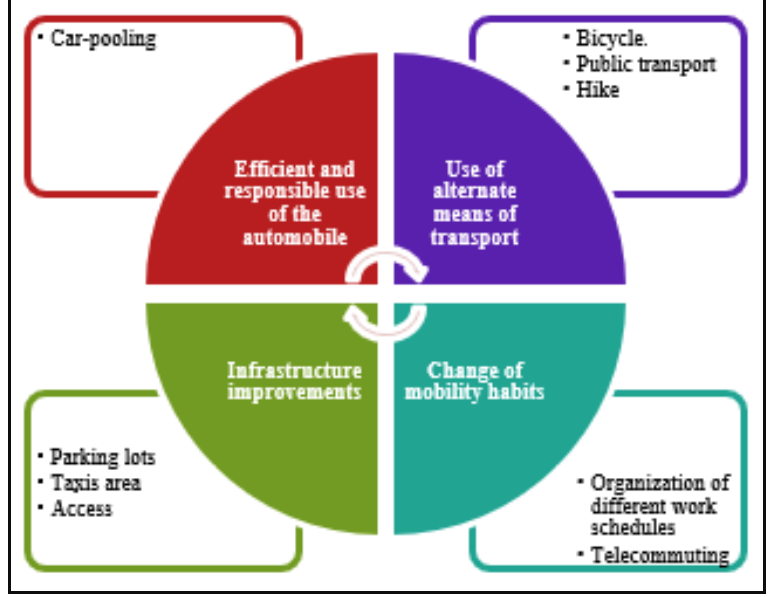

Fig. 1. Typology of strategies - PEMS

From these four strategies, between 2013 and 2018, the following activities have been generated and implemented:

a. Efficient and responsible care use

- Encourage the use of the shared vehicle known as car-pooling

- Implementation of the app (Javeriana Mobility Application) for car-pooling, taxi, motorcycles, bicycles and walks.

- Promote plan for the users of the application.

- Active participation in the vehicle-restriction day planned by the Bogota City Hall.

b. Use of alternative means of transport

- Encourage the use of bicycles and other means of transport.

- Incentive plan for bicycle users.

- Organization of caravans for bicycles and walks.

- Bicycle loan.

- Bicycle repair site at the University.

- Encourage the use of shared public transport and procurement of a provider to offer different routes to and from the university.

- Encourage the use of the integrated transport system by the location of a selling and reloading smart-cards site.

c. Changing mobility habits

- Pilot tests are being carried out so that some job-positions can telecommute some days of the week.

- Organization of different working schedules to reduce the mobility during the peak hours.

d. Infrastructure improvements

- Increase in bicycle parking spaces.

- Improvement of bicycle parking infrastructure (lockers, bicycle repair site, water fountain).

- Definition of preferential parking spaces for users who share their vehicle.
The implementation of the four mentioned strategies is supported in a transversal pillar conceive as "Culture and education". This pillar seeks to sensitize the university community, generate awareness, and modify habits that produce changes and improve the social and environmental impacts that the problem of mobility generates for the city of Bogotá and its inhabitants. This has been done with the following actions: awareness and information campaigns to the university community on mobility issues, conferences and discussions with the Mobility Secretariat and experts on good practices, Javeriana mobility weeks, competitions, creation of a digital community on Mobility (social networks), information to users through the different communication channels of the University and socialization of the results of fingerprint measurements and mobility diagnosis.

\section{Discussion}

During these years, we have reached certain goals that we consider important to be shared, both at the university level and at the city level:

- The number of spaces available for bicycle parking was significantly increased. Today we have three bike parking areas, increasing from 48 places in 2012 to 382 places in 2018.

- The number of registered bicycle users increased significantly, from 180 users in 2012 to 917 in 2017 , thanks to awareness campaigns and activities such as "Semana mejor en Bici" "a week, better by biking" and "Javeriana en Bici" "Javeriana by Bike".

- The use of the bicycle loan service has increased. Thanks to this service, several opportunities are offered to the members of the university community to carry out their bike trips to know their advantages and eventually to convert them into permanent users. In 2015, 252 users made 910 round-trips through this service.

- In the days of the "car-restriction day" planned by the Mayor of Bogotá, the number of users transported to the University by bicycle increased by $55 \%$.

- There have been 2.830 downloads of the Javeriana Mobility application, a tool that allows members of the Javeriana university community to share their vehicle, and to organize 1) routes for walks and 2) mobilization by bicycle or motorcycle.

- The use of the shared vehicle or car-pooling has increased by $27 \%$, between 2016 and 2017 .

- The "Golded seal" was received from the Bogota Mobility Secretariat for having a bicycle-parking infrastructure with standards of excellence in quality, safety and service.

- Recognition was received by the Mobility Secretariat of the city for having mobilized the largest number of managers on bicycles in 2017.

- Due to the achievements, the Javeriana University received the recognition of the District Mobility Secretary and the District Department of the 
Environment in 2016 for its active contributions that have actively contributed to improving the mobility of the city through the different and permanent strategies implemented.

\section{Conclusions}

The problem of mobility in the city of Bogotá is of great impact for the lives of those who live there; it is everyone's problem. That is why all support has been given from the management levels of the institution to the "Javeriana Mobility Program", which supported in generating culture, education and awareness, has designed and implemented strategies that mitigate the effects of mobility in the university community. In the year 2018, another measurement will be carried out in order to have a comparison parameter with the diagnosis made in 2015 and thus determine whether the strategies and actions implemented have had the expected effect or make the corresponding adjustments. The University has a high commitment to 5 . the solution of this problem and it hopes to contribute the best way, also being frame under the Encyclical of Pope Francis "Laudato si" on care for our common home.

\section{References}

1. Transmilenio, mass transport system. Available online at: http://www.transmilenio.gov.co/

2. Observatory of Mobility of Bogotá. Integrated Information System on Regional Urban Mobility SIMUR. Available online at http://www.simur.gov.co/SimurVisorBoletinWA/2 016.html\#PDF/1

3. Universidad de Los Andes, Fundación Chévrolet, Andi Seccional Cundinamarca-Boyacá, PEMS. Diagnóstico de Movilidad, Resultados Julio 2016.

4. Planes Empresariales de Movilidad Sostenible PEMS. Diagnóstico de Movilidad Pontificia Universidad Javeriana (2016). 